DOI: http://dx.doi.org/10.23925/2176-2767.2018v63p396-402

Data de submissão: 22/02/2018 Data aprovação: 24/08/2018

\title{
RESENHA
}

\section{HISTÓRIA DAS EMOÇÕES: PERCEPÇÕES A PARTIR DA OBRA DE CAPDEVILA E LANGUE}

DULCELI DE LOURDES TONET ESTACHESKI*

CAPDEVILA, Luc; LANGUE, Fréderique (Org.). Le passé des émotions. D'une histoire à vif. Amérique Latine et Espagne. Rennes: PUR, 2014. 204 p.

Os sentimentos e as emoções das pessoas podem ser pensados historicamente? A escrita da história pode considerar as dores dos sujeitos que participaram dos eventos analisados? Essas questões são pertinentes para a historiografia e remetem-nos a pensar em uma história viva, ou "vivida" como sugerem Capdevila e Langue ${ }^{1}$, que não desconsidera as subjetividades das pessoas que a experenciaram. Para quem se aventura nessa perspectiva histórica a leitura da obra 'Le passé des émotions', organizada por Luc Capdevila e Frédérique Langue é fundamental.

Luc Capdevila é um historiador francês que possui como objetos centrais de suas pesquisas a guerra e as relações de gênero, pensando a França e a América Latina. ${ }^{2} \mathrm{O}$ historiador Frédérique Langue estuda a história do tempo presente e a escrita da história nos mundos ibéricos. ${ }^{3}$ Nesta obra, organizada por ambos que são pesquisadores do Centre National de la Recherche Scientifique, as emoções humanas são objeto de reflexão. O 
livro é dividido em duas partes: a primeira é composta por seis capítulos que se pautam na temática da memória dos corpos; e segunda conta com sete capítulos que refletem sobre as emoções da memória.

No texto de abertura da obra, 'Le prisme des émotions', Capdevila e Langue destacam que ao pensar as emoções relacionadas às memórias, historiadores/as correm o risco de escrever uma "história compassiva" que alimenta "o pecado da empatia com a testemunha", mas ao mesmo tempo, "para o historiador do tempo presente as emoções são as 'realidades penhoráveis’ de uma história encarnada." ${ }^{4}$ Retomando o pensamento de Conan e Rousso ${ }^{5}$ sobre o passado que não passa e salientando que o presente se interroga à luz de suas inquietudes, defendem que a História não é apenas um estudo do passado pelo passado, mas que os eventos ocorridos agem, ou fazem agir, no presente, seja na memória dos que a eles sobreviveram, seja na interpretação e reinterpretação que fazem as pessoas de hoje desses mesmos episódios e do sentido que isso tem para suas vidas. ${ }^{6}$ Essa ação da história nos sujeitos é também emocional e não apenas racional, a forma como um evento afeta a pessoa a move e isso não pode ser desconsiderado. Se por um lado existe o risco da história compassiva e da empatia com a testemunha na escrita, por outro, a negação das emoções confere o risco de uma história esvaziada de vida.

A proximidade entre passado e presente, as relações entre essas temporalidades mediadas pelas emoções, é foco das pesquisas apresentadas na obra que tem como palco de análise o mundo latino-americano e a Espanha. A relação dos povos antes colonizados com seu passado e a atualidade de circulações culturais permeiam os textos que compõem o livro. 
Num primeiro tempo, questionamos porque e como as emoções poderiam mostrar vestígios de uma experiência do passado, revelando no corpo um arquivo de sensibilidades. A segunda parte faz as articulações entre emoções coletivas, memórias e mobilizações políticas. ${ }^{7}$

Assim, os seis textos que compõem a primeira parte trazem reflexões sobre poética, retórica e política das emoções (Javier Moscoso); sobre sentimentos como a raiva entre pessoas deficientes que se sentiram injustiçadas no campo profissional, especialmente aquelas que passaram por processos de readaptação (Gildas Brégain); sobre o medo da violência durante a Guerra Civil Espanhola quando mulheres ditas republicanas sofriam abuso sexual (Maud Joly); o ódio político na Argentina, pensado como uma emoção que afeta os comportamentos coletivos, cuja pesquisa permite refletir sobre as condições da destruição de laços sociais (Moira Cristiá); o trauma relacionado à morte violenta de mulheres na cidade mexicana de Puebla; a exposição dos corpos de criminosos e vítimas apontados como portadores de degradação social, especialmente por pertencerem às camadas populares (Rosalina Estrada Urroz) e uma discussão sobre a política da morte e as emoções políticas na Argentina contemporânea, analisando funerais públicos para pensar a relação entre o corpo e a multidão, pensando a interpretação política do ato de expressar emoções em público (Sandra Gayol). O corpo, e as sensações, as emoções que se manifestam nele são evocadas e analisadas nesse primeiro momento do livro.

Nos sete capítulos seguintes, da segunda parte do livro, as memórias e as emoções e mobilizações que elas causam conduzem as reflexões. Alejandro Gómez discute sobre o papel dos historiadores das emoções Projeto História, São Paulo, v. 63, pp. 396-402, Set.-Dez., 2018. 
frente ao que chama de revolução das ciências cognitivas, entendendo que a interdisciplinaridade pode contribuir significativamente para as pesquisas em todas as áreas. Frédérique Langue analisa o ressentimento e o messianismo na Venezuela a partir da formação de um sentimento de civismo quase religioso em relação a heróis nacionais, enquanto Sophie Milquet tem como objeto de pesquisa os romances que trazem memórias, testemunhos de mulheres sobre a Guerra Civil Espanhola, entendendo que tais relatos se constituem em uma contra-memória frente à memória oficial do franquismo. A percepção da população de hoje sobre o golpe chileno de 1973 é analisada por Manuel Gárate Château e a experiência das guerras civis no Uruguai é objeto de estudo de Maria Laura Reali. Luc Capdevila escreve sobre o Paraguai afirmando que a intensidade emocional da relação coletiva com o passado faz dele um país singular na América do Sul e, no final, Capdevila divide com Frédérique Langue o texto que retoma o título da obra, articulando o uso das emoções, ou do que chamam de "memórias sensíveis" ${ }^{\prime}$, como possibilidade de análise histórica.

Uma das autoras citadas na obra é Arlette Farge que em seu mais recente livro publicado no Brasil, 'Lugares para a História", reflete sobre uma escrita da história que se ocupe do que seja relevante para a comunidade, para as pessoas, e confronte passado e presente. A proposta é pensar questões que encontrem eco no presente, como sofrimento, violência, guerra, porém em uma perspectiva que considere os sujeitos e suas experiências singulares. Para a autora, a historiografia tem lidado com grandes catástrofes humanas sem considerar as emoções que elas causam, como se os eventos em si fossem mais importantes que as pessoas neles envolvidas. Suas dores são comumente tratadas como meras fatalidades. 
Para ela, historiadores/as precisam entender que a "dor significa, e a maneira como a sociedade a capta ou a recusa é extremamente importante". ${ }^{10}$

Seguindo por essa perspectiva, Capdevila e Langue afirmam que é preciso perceber a importância dos contextos políticos e culturais que promovem a expressão das emoções, dar-lhes significado, entendendo que essas emoções atendem a códigos, hierarquias e regulamentos sociais. ${ }^{11}$ Para Moscoso, no texto em que aborda a poética, a retórica e a política das emoções $^{12}$, a história das experiências subjetivas deve muito às relações que se estabelecem entre História e Antropologia e entre História e memória. $\mathrm{O}$ autor salienta que mesmo com as dificuldades relacionadas às fontes, aos arquivos, às narrativas, não se pode desistir de "uma história para os vivos e não para os mortos". ${ }^{13}$

Como a história é escrita no presente e não no passado, é possível se concentrar nas materializações culturais da experiência do passado, não como uma forma de valorização ou de construção de uma memória, mas como um exercício intelectual, moral e político, uma pesquisa de elementos que permitam a cristalização do fluxo da vida, seja na teoria científica, seja na prática clínica, seja num código penal, ou em uma obra de arte. ${ }^{14}$

O que Farge ${ }^{15}$ chama de lugares para história, aquilo que é eco hoje, um resquício, de um determinado passado. A autora afirma que "buscando conhecer outro tempo, não escapamos do nosso, e, se este último, como o faz hoje, se arranca brutalmente do passado, a história se engaja também nessa 'realidade' para encontrar seu sentido". ${ }^{16}$ Uma história que dê conta de perceber a significação dos eventos para as pessoas e assim elabore 
entendimentos, racionalizações que ajudem a agir no presente com maior consciência. A autora destaca que racionalizar o sofrimento, por exemplo, possibilita a compreensão dos dispositivos que o desencadeiam e "fornecer os meios intelectuais de suprimi-los ou de evitá-los"17.

Citando manifestações populares da Argentina entre os anos 19902000 que levavam a público rostos de pessoas envolvidas com o período de repressão da ditadura, representações teatrais suscitadas pelas comissões da justiça e da verdade na Argentina e no Paraguai, entre outras ações, Capdevila e Langue as definem como "momentos de emoções" que "testemunham uma profunda interiorização do passado"18 e o desejo de uma reescrita da história. Para os autores "o campo emocional que irradia o ambiente de estudos e alimenta as dinâmicas da pesquisa, é simultaneamente um forte constrangimento e uma formidável oportunidade de captar a história vivida."19 A história das emoções pode confrontar a historiografia, pode pensá-la por outras perspectivas. Pode constranger iluminando aspectos antes escondidos, mas permite uma compreensão profunda da subjetividade humana frente a diferentes eventos considerando significativa toda experiência.

\section{Notas}

\footnotetext{
* Doutoranda do Programa de Pós-Graduação em História da Universidade Federal de Santa Catarina. Mestre em História pela Universidade Federal do Paraná. Professora colaboradora do curso de História da UNESPAR, campus de União da Vitória/PR. Número do ORCID: 0000-0002-4059-5606.

${ }^{1}$ CAPDEVILA, L.; LANGUE, F. (Org.). Le passé des émotions. D’une histoire à vif .Amérique Latine et Espagne. Rennes: PUR, 2014.

2 PEDRO, J. M. As guerras na transformação das relações de gênero: entrevista com Luc Capdevila. Revista Estudos Feministas. 13 (1), jan/abril, 2005.
} 
${ }^{3}$ LANGUE, Frédérique. Escribir la historia Del tiempo presente o el imperio de las emociones. Revista Digital de la Escuela de Historia. Unr/año 5, n 9, Rosario, 2013. Disponível em: < https://dialnet.unirioja.es/descarga/articulo/5537485.pdf > . Acessado em 04 de janeiro de 2017.

${ }^{4}$ CAPDEVILA, L.; LANGUE, F. op. cit., p. 7.

${ }^{5}$ Obra citada pelos autores: CONAN, É.; ROUSSO, H. Vichy, un passé que ne passé pas. Paris: Gallimard, 1996.

${ }^{6}$ Jörn Rüsen em suas obras faz considerações interessantes sobre a história pensada a partir dos interesses do presente. Em uma conferência sua em Curitiba em 2011, na Universidade Federal do Paraná, intitulada 'A história entre a modernidade e a pós-modernidade', ele chega a afirmar que a história não estuda o passado e sim o presente, pois é nesse tempo que surgem as inquietações que nos movem a pesquisar a história. Para o autor é a nossa consciência histórica que nos faz agir no mundo hoje. O presente problematizado e o passado compreendido nos fazem perspectivar um futuro e isso move nossas ações. (RÜSEN, J. O desenvolvimento da competência narrativa na aprendizagem histórica: uma hipótese ontogenética relativa à consciência moral. In: SCHMIDT, M. A.; BARCA, I.; MARTINS, E. de R. Jörn Rüsen e o ensino de História. Curitiba: UFPR, 2010.)

${ }^{7}$ CAPDEVILA, L; LANGUE, F. op. cit., p. 10.

${ }^{8}$ CAPDEVILA, L; LANGUE, F. op. cit., p. 197.

${ }^{9}$ FARGE, A. Lugares para a história. Belo Horizonte: Autêntica, 2015.

10 Idem. p. 19.

11 MOSCOSO, J. Poétique, rhetórique et politique des émotions : le drame de l'experiénce. In : CAPDEVILA, L; LANGUE, F. op. cit. p. 13.

12 Ibid., p. 25.

13 Ibid., p. 25.

${ }^{14}$ MOSCOSO, J. Poétique, rhetórique et politique des émotions : le drame de l'experiénce. In : CAPDEVILA, L.; LANGUE, F. op. cit., p. 25.

${ }^{15}$ FARGE, A. op. cit.

${ }^{16}$ Idem. p. 129.

${ }^{17}$ FARGE, A. op. cit. p. 23.

18 CAPDEVILA, L; LANGUE, F. Le passe dês émotions, mémoires sensibles et histoire à vif, Amérique Latine et Espagne. In : CAPDEVILA, L; LANGUE, F. op. cit., p. 197. 19 ibid., p. 198. 